\title{
Tilting at imaginary windmills: a comment on Tyfield
}

\author{
YANN GIRAUD \\ Duke University \\ E. ROY WEINTRAUB \\ Duke University
}

\begin{abstract}
In the inaugural issue of this journal, David Tyfield (2008) used some recent discussions about "meaning finitism" to conclude that the sociology of scientific knowledge (SSK) is an intellectually hopeless basis on which to erect an intelligible study of science. In contrast, the authors show that Tyfield's argument rests on some profound misunderstandings of the SSK. They show that his mischaracterization of SSK is in fact systematic and is based on lines of argument that are at best incoherent.
\end{abstract}

Keywords: economics of science (ESK), sociology of scientific knowledge (SSK), science studies, meaning finitism

JEL Classification: B40, Z13

In the inaugural issue of this journal, David Tyfield (2008) examined the connection between the economics of scientific knowledge (ESK) and the sociology of scientific knowledge (SSK). He argued that, pace Wade Hands (1994), SSK can underwrite the claims of ESK. Indeed, for Tyfield, Hands's argument itself is a bit stronger suggesting that SSK necessarily underwrites the claims of ESK. Consequently the weakness, or incoherence, of SSK must do great damage to any attempt to employ economics as explanatory for the development of science.

Tyfield then re-presented SSK as seen by Hands, and recapitulated the reflexivity problems that were claimed by Hands to beset SSK. Tyfield argued that the issues are even more severe than Hands had suggested in 1994 and that, in particular, it is a necessary implication of 
SSK that it employ and commit to employing the idea of "meaning finitism". Using some recent discussions about "meaning finitism" as it has appeared in the philosophical literature, Tyfield concluded that SSK is an intellectually hopeless basis on which to erect an intelligible study of science.

In what follows we shall show that Tyfield's argument rests on some profound misunderstandings of the SSK; misunderstandings that amplify Wade Hands's own confusions. We shall show that his mischaracterization of SSK is in fact systematic and is based on lines of argument that themselves are either incoherent or tendentious or both. Furthermore, we shall argue that Tyfield appears unaware of a scholarly literature that provides more than sufficient evidence of the futility of his claims, a literature that opponents of SSK who routinely mischaracterize their opponents' arguments have not engaged.

Tyfield's argument sets out stating that:

[...] the philosophical problems of SSK are much more profound than the familiar problems of "reflexivity". In particular, finitism is intelligible only if it is false. It follows that SSK is not merely selfrefuting, but, insofar as it holds onto finitism, it is unintelligible. If SSK is even to be able to sustain its own research program, let alone act as role model for an ESK, it must therefore forsake finitism (Tyfield 2008, 62).

To develop this argument, Tyfield notes that he must work out the nature of SSK. He correctly says that "SSK is the empirical examination of the generation of scientific knowledge as an open-ended and contingent social process, situated in specific socio-historical locations" (p. 63). He goes on to say that:

The history of science reveals that the development of scientific knowledge is ridden with controversy. The 'facts' can be, and are, interpreted in many different ways. It follows that the 'facts' themselves cannot determine scientific knowledge. SSK instead turns its attention to the causal explanation of how different beliefs come to be believed (p. 64).

He claims that this particular set of ideas developed around 1982, but we note that the literature on this issue has developed quite extensively since then, and has moved far beyond such simplistic notions. For example, Latour (1999) reintroduced ideas of mutual stabilization of beliefs about nature and nature itself-an idea discussed 
fully by Fleck (1979) as early as 1935-which undermine any argument about a one-way causality that Tyfield seems to believe characterizes SSK. We shall return to this idea of mutual stabilization later.

The key move in Tyfield's paper-a move which we assert can be found in every paper which attempts to claim that SSK is self-refutingmakes its first specific appearance when he writes:

Starting from the Kuhnian insights into the social relativity of beliefs and the theory-ladenness of observation, and the broader changes in post-positivist (e.g., Quinean) philosophy towards a nonfoundational epistemology, SSK argues that whether our beliefs are true or false is entirely inaccessible to us, for we cannot step outside ourselves and our social world in order to compare our beliefs with the world as it is. It follows that there is no ultimate appraisal of scientific knowledge, only the situating of it in further scientific understanding of how 'scientific' knowledge is produced and the status of that 'knowledge' (Tyfield 2008, 64).

This paragraph requires scrutiny. Consider the phrase "SSK argues that whether our beliefs are true or false is entirely inaccessible to us, for we cannot step outside ourselves and our social world in order to compare our beliefs with the world as it is". It is important to realize there is no citation provided to ground this claim of Tyfield's, a claim which he regards apparently as self evident to anyone who reads anything about SSK. It is not however self evident, and is in fact nonsensical. SSK does not argue that whether our beliefs are true or false is entirely inaccessible to us, because SSK's or the pragmatist's use of true or false is not in fact a matter of "comparing our beliefs with the world as it is". That may be Tyfield's use of true or false, but it is not that of SSK. For us, we have no trouble whatsoever appraising beliefs as true or false, having a very good idea of whether the application of those words to beliefs is coherent.

Beliefs that are true or false for any pragmatist concern the work that the beliefs do, the commitments they engender, and the problems they resolve at a particular time and place and community. We have no problem saying that we cannot assess the truth or falsity of string theory, but that string theorists can use those words and have a very clear idea what it is they are agreeing to. We have a belief that it is true that the sun will rise tomorrow. That belief is very useful, and through a long set of contingent processes in which that belief has been useful, we feel very easy saying that it is true that the sun will rise tomorrow. We 
feel quite comfortable, that is, saying that we have a very clear notion of true and false as applied to these beliefs. Where then is Tyfield's problem located? It is located of course in Tyfield's insistence that we use true and false the way he wishes to use true and false. We agree (how could we not?) that whether our beliefs are Tyfield true or false is inaccessible to us, for we cannot step out of ourselves and our world to directly perceive the world as it is. That project of stepping outside ourselves to see the world as it really is-or should we say as it reallytruly is-is a project in which we have no interest. For someone who is studying how scientists change their beliefs, that which really-truly is comes into being simultaneously with the beliefs themselves, that is, beliefs change in the course of doing the work for which having the beliefs is important. The beliefs and the evidence mutually reinforce, mutually stabilize, each other.

This shift in meaning in Tyfield's argument, a shift which moves the discussion from pragmatist meanings to anti-pragmatist meanings, of course entails that the pragmatist meanings are incoherent using the non-pragmatist vocabulary. They are "thus" absurd or self refuting. Anti-pragmatists practice this intellectual sleight of hand to their selfevident delight. That Tyfield is aware of his illegitimate move appears on the very next page (p. 65) in his footnote 10 where he states that "the two communities party to this debate, philosophers and sociologists, tend to use the word 'extension' in two slightly different ways [...] I will be using the term in the philosophical sense." This philosophical now you see it, now you don't adorns almost every page of his assault. For example, Tyfield writes that:

It follows that, pace 'rationalist' philosophy of science, neither logic nor the empirical evidence determines the development of science. If this is the case, it follows that something else must determine what scientists believe and how those beliefs change (p. 67).

To assert that for SSK pragmatists, SSK students of the development of science, neither logic nor empirical evidence determines the development of science is simply strange. Who has ever asserted that evidence and logic do not both constrain and shape the development of science? Pragmatists are very comfortable saying that the kind of arguments used, and the empirical evidence used to support various claims, develop pari passu with scientific theories. Theories and evidence grow together. The evidence of position of the planets 
developed with astrologers' theories and astrological argumentation, just as the evidence of planetary movement developed with theories of planetary motion. How could it be otherwise? If you don't know what an egg looks like, if you don't know an egg from a hole in the wall, questions about chickens and eggs make little sense.

The classic example in economics of this misunderstanding is quoted by Tyfield as he reproduces Wade Hands claim that:

Many of the advocates of the SSK claim to undermine the hegemony of the natural sciences by showing that what is purposed to be objective and 'natural' is neither one of these things, but rather simply a product of a social context in which it is produced. If this is true for all human inquiry, then it must be said for the SSK as well; this makes everything socially/context dependent and thus relative (Hands 1994, 92; Tyfield 2008, 69).

Tyfield immediately follows Hands's comment with his own:

It follows that there would be no grounds, other than social happenstance, for accepting any belief, and this includes SSK itself. Hence the "problem of reflexivity" is that if the SSK argument is correct, we have no grounds to accept SSK itself (pp. 69-70).

This argument repeats itself over and over again in Tyfield's paper. For example, he says that:

[...] if we cannot take account of truth or falsity, we have no grounds on which to discriminate ' $\mathrm{X}$ ' from 'not X' so that we can believe both. As such, the 'truth' and 'falsity' of our beliefs is a necessary condition of the possibility of rational judgement, and without judgement we fall prey to an all-consuming relativism that makes all beliefs equally 'defensible'.

In other words, if we cannot refer to 'truth' or 'falsity' (as per symmetry), we must forsake altogether all use of these concepts, and this includes tacit presupposition as well as explicit usage. But this rules out rational judgment and so abandons us to relativism. (p. 72)

Again, here David Tyfield provides no evidence whatsoever that anybody has ever said anything along these lines. There are no citations, no claims that someone said this, or even someone said something that was close to this. All that is presented is a set of statements which are so absurd as to call into question the judgment of anybody who 
subscribes to such pragmatist views of truth or to any coherence view of the use of words like true or false with respect to beliefs. Quoting David Bloor saying in 1991 that knowledge is "a system of beliefs that a community collectively accepts as knowledge" is hardly something to make one's jaw drop.

Equally problematic is Tyfield's using other quotations out of context in an elliptic manner that renders their interpretation difficult for the uninitiated. For example, Tyfield writes in footnote 16 (Tyfield 2008, 73n) that Hands uses the expression 'throwing oneself out with one's own bathwater', while acknowledging that Hands did so not in direct relation to SSK. But he does not then go on to reveal that Hands is actually referring to a neoclassical economics based philosophy of science, which was used by James Wible to argue against the hegemony of neoclassical economics. Linking Hands's criticism of the neoclassical economics of knowledge (e.g., Wible) to the internal debates that occurred in the field of SSK is at best confusing and at worst misleading. Those internal debates, indeed, are referred to throughout Tyfield's paper to argue against the consistency of SSK, but the paper itself provides no insight into the content of those debates. Similarly, Tyfield's inclusion of David Hess's assertion that "[in SSK studies] sociological theories and (anti) philosophical arguments upstage [its empirical work]" (Hess 1997; Tyfield 2008, 69) is rather jarring when one knows that Hess, in the same book, argues that although he is critical of "the social relativism that characterizes a corner of the social science community", he is "more disturbed by the attackers' dismissive caricatures and distortions of a huge volume of theory and research" (Hess 1997, 1, emphasis added). Tyfield is thus attacking precisely nothing.

That the claims we are making are unremarkable may be seen from examining the work of scholars who have explored this "self refutation" charge. The best single discussion of this is in Barbara Herrnstein Smith's (1997) "Chapter 5: Unloading the self-refutation charge". Smith shows that Tyfield's kind of critique is as old as Socrates's examination of Protagoras's doctrine in Theaetetus and that the same string of arguments has been repeatedly used over the course of intellectual history to disembowel any new stream of philosophical innovators such as "the relativist, Hume, the epistemological skeptic, Nietzsche, the perspectivist, and, in our own era, postmodernists such as Kuhn, 
Feyerabend, Foucault, Derrida, Lyotard, Goodman and Rorty" (Smith 1997, 73-74).

Because the traditional philosopher of science often believes that one's epistemological position also sustains some higher values in society, such as moral judgment and scientific progress, that philosopher must also believe that beating the pragmatist will keep us from sinking into social anarchy, moral relativism, solipsism, or intellectual chaos. It is therefore necessary to ask: against which of those perilous evils does Tyfield wish to inoculate us? What higher purpose legitimates Tyfield's excoriation of SSK? The answer to this question is given at the end of the paper when the author returns to the issue of ESK. Tyfield, recall, believes that SSK necessarily undergirds ESK. He asserts that "ESK, if it is to do anything at all, must be able to offer a critique of how and where the imposition of economic imperatives on scientific research has a detrimental effect on the 'scientific knowledge' thereby produced" (Tyfield 2008, 82). ESK however is economic analysis, not an oppositional stance to modern scientific practices. Nor of course does SSK, or science studies, provide such a critique, at least if the word "critique" is understood as an attempt to valorise the practices of scientists who are engaged in profitdriven research. SSK has no interest in determining what a virginal scientific knowledge-if it ever existed-would look like. Instead, SSK can provide a careful examination of the ways industrial and academic research have evolved and accordingly tell a story about the construction of scientific knowledge that may annoy the non-pragmatic philosopher of science. ${ }^{1}$ Tyfield's own annoyance confirms the claim just made.

\section{REFERENCES}

Fleck, Ludwik. 1979 [1935]. Genesis and development of a scientific fact. Chicago: University of Chicago Press.

Hands, D. Wade. 1994. The sociology of scientific knowledge: some thoughts on the possibilities. In New directions in economic methodology, ed. Roger Backhouse. London: Routledge, 75-106.

Hess, David. 1997. Science studies: an advanced introduction. New York and London: New York University Press.

\footnotetext{
${ }^{1}$ We invite the reader interested in these issues to explore Shapin's (2008) new book. This acclaimed volume encourages a fair reading of what recent SSK has to offer, instead of a scandalized reconstruction of its so-called anti-philosophical epistemology.
} 
Latour, Bruno. 1999. One more turn after the social turn. In The science studies reader, ed. Mario Biagioli. London: Routledge, 276-289.

Shapin, Steven. 2008. The scientific life: a moral history of a late modern vocation. Chicago: Chicago University Press.

Smith, Barbara Herrnstein. 1997. Belief and resistance: dynamics of contemporary intellectual controversy. Cambridge: Harvard University Press.

Tyfield, David. 2008. The impossibility of finitism: from SSK to ESK? Erasmus Journal for Philosophy and Economics, 1 (1): 61-86. http://ejpe.org/pdf/1-1-art-3.pdf

Yann Giraud is a postdoctoral fellow at the Center for the History of Political Economy, Duke University. His research focuses on the place of visual language in recent economics.

Contact e-mail: <yann.giraud@duke.edu>

E. Roy Weintraub is a professor of economics at the Economics Department, Duke University. His research has focused on the history of the interconnection of the mathematics and economics communities in the twentieth century.

Contact e-mail: <erw@duke.edu>

HOPE Center website: <www.econ.duke.edu/CHOPE/> 